AUTHOR:

M.P. Sebola

AFFILIATION:

Department of Public Administration

University of Limpopo

CORRESPONDENCE TO:

Mokoko Piet Sebola

POSTAL ADDRESS:

P.O.Box 15477, Florapark, 0699

DATES:

Published: 21 Aug 2018

HOW TO CITE THIS ARTICLE:

Sebola, M.P., 2018. Peer review,

scholarship and editors of scientific

publications: the death of scientific

knowledge in Africa. KOERS - Bulletin

for Christian Scholarship, 83(1).

Available at: https://doi.org/10.19108/

KOERS.83.1.2314

COPYRIGHT:

(C) 2018. The Author(s).

Published under the Creative Commons Attribution License.

\section{PEER REVIEW, SCHOLARSHIP AND EDITORS OF SCIENTIFIC PUBLICATIONS: THE DEATH OF SCIENTIFIC KNOWLEDGE IN AFRICA}

\author{
ABSTRACT \\ This paper argues that the manner in which the scholarship peer review as a process of \\ scientific quality is conducted and perceived in the editorial arena is a cause of insufficient \\ knowledge production in Africa and developing countries. Arguments still persist that the \\ developing countries such as Africa contribute at least 1.25\% of the world knowledge \\ production. This paper does not aim to support the idea that the peer review process of \\ scholarship in the publication of scientific material is unnecessary, but arques that the manner \\ of using it to judge scholarship quality is often flawed in many academic publications. This \\ paper uses an analytical approach from literature sources to argue that the usage of peer \\ review without considering the complex process affecting peer review will result in the death \\ of knowledge in the academic enterprise of developing countries such as Africa. This paper \\ concludes that only if editors of scientific publishing can conduct peer reviews in an ethical \\ manner without biasedly directing knowledge, knowledge generation will increase to solve \\ economic problems in Africa.
}

\section{INTRODUCTION}

The contribution of knowledge generation by Africans in scholarship to solve political, economic and social problems in the continent is arguably low in comparison to other countries on the globe. African literature on academia, though little acknowledged, but seems to depend too much and also finding and seeking its reference and legitimacy from academic viewpoints of the developed countries. That also cannot be a problem because indeed to improve our understanding we need to learn from the successful cases of knowledge dissemination which in this case such knowledge is from the developed nations. The use of knowledge of science from the developed nation is not a problem per se because it helps us to improve our own as the developing nations in Africa. But what cannot be ignored is the knowledge power play between the developed and the developing nations for which in this knowledge power play the developing nation's influence is kept under the level of the game. This paper raises a question: Is the peer review process and the role of editors in academic publishing assisting in the knowledge creation of African scholarship? In order to answer this question, this paper will keep focus its relevance on the following aspects: The Gate Keeping Theory, The Role of Editors in Scientific and academic writing, Peer Review in Academic or Scientific writing, The Status of knowledge generation in Africa and whether knowledge is created through the Peer Review Process of Scientific Writing.

\section{THE GATE KEEPING THEORY}

This paper is grounded on Gate keeping theory because in it I assert that editors of journals in scholarly environments control which knowledge should be published - for their own purpose than the authors' purpose. Gate Keeping is believed to be a process 
of controlling information as it moves through a gate or filter (Barzilai-Nahon, n.d:101). According to Schoemaker and Vos (n.d: 75) it is the process whereby some things are chosen and others rejected. The concept is indeed used to metaphorically refer to editors of academic scholarship and the media as people that stand on the gate to determine which knowledge is passed on to the readership community or not. The term is said to have been coined for the first time in 1947 by a Psychologist Kurt Lewin who investigated the different eating habits in families (Rosengren, 1997; Bouhnik \& Giat, 2015). He found out that women or housewives in families control the decision regarding the eating habits and have created behavioural obstacles and incentives in the context. In his study he called women the "gate keepers". It is, however, acknowledged that from its origin, the theory had nothing to do with communication of information. Schoemaker, Eicholz, Kim \& Wringly (2001:233) mentioned that Lewin himself "suggested that his theory of how "items" are selected or rejected as they pass through "channels" could be applied to the flow of information".

It is also acknowledged that the concept is fragmented in terms of epistemology, theory, models and vocabulary because of its research challenges and orientation handled from various disciplines or fields of study. In the media gatekeeping may be associated with the Editors' intentions to give coverage to specific individuals and deny the others or decide to publish one story and refuse to publish the other. Cassidy (2006) calls it "One of the most easily accessible theories" in mass communication. Clayman and Reisner (1998) argue that the front page story is a sign of an editor having gate kept other stories to be in insignificant pages of the press.

Editors in academic journals also have the same functions of sifting relevant and appropriate information fit for the purpose of the journal leaving others which do not seem to serve their purpose. In executing such functions they have to determine who comes in or who does not enter the scholarly gates of their journals. While the concept gate keeping is thought of as being rude as applied to editors of scientific journals, Sato (2012) says that "salesman" could be a more appropriate term to characterise the aggressive aspects of editorial work". This I guess had to do with the fact that journals indeed exist to sell a particular scientific perspective than the opposite perspective that can be pushed by authors of a different opinion. Many argue that peer review in scholarly journals does nothing other than keeping the old scientific orthodox in which the status quo of unconventional ideas and science is maintained (Lipworth \& Kerridge, 2011:2). Although on a different level, Maserumule (2012) argues that "In appropriating to itself the self-proclaimed epithet of the connoisseurs of scholarship, swashbuckling its gerontological imagination as the finite of science, the old disturbs the birth of the new". The argument as expressed by the former is very significant in gate keeping arguments as it is also evidenced that no alternative theory is acceptable by any journal since journals exists not to challenge any existing theory of their scope but to maintain and channel the knowledge direction determined by the editor whether old or new. The pursuance of truthful knowledge by academic journals remains a contested scholarly terrain. The abuse of editorial power in scholarly publication is very much known (Roth, n.d:2) although rarely publicised as authors fear being kept out of the gate for life. Moreover, it should be fairly acknowledged that gate keeping is done for various reasons which the implementers call the truth when it suits their perspectives. In the medical fraternity Doctors may gate keep information to the patients in order to avoid either burdening the patient or his relatives about his or her health condition (Kars, Van Thiel, Van Der Graaf, Moors, De Graaf \& Van Delden, 2016). Many journal editors indeed when gate keeping the entrance for other scholars will do that in the name of protecting the integrity of the journal against sloppy work from other specific authors or keeping the high quality and standard of the journal.

\section{PEER REVIEW PROCESS IN ACADEMIC WRITING}

A peer review in scientific writing is also referred to as Scholarly refereeing (Harley \& Acord, 
2011:1). In this process the experts in the field evaluate scholarly work to ensure a high quality of published scientific material (Editage Insight, 2013:1). The general purpose of a peer review process is mainly to ensure quality assessment and control of the academic world (Harley, Accord \& Earl-Novell, 2010:4). One of the important functions of peer review process include its ability to detect fraud before publication (Ancker \& McLellan, 2003:1), even though such can still be detected by careful readers after material has been published. While it is not the intention of the peer review process in academic environment to do the opposite functions, the peer review process often leads "to gatekeeping to regulate entry of new ideas into scholarly fields" (Harley \& Acord, 2011:1). Maserumule (2012) on the other hand noted that gate keeping "is characterised by a strong network of gatekeepers used to ensure that the emerging ideas that challenge a dominant paradigm remained perpetually emerging on the periphery of scholarship in which the new is often dismissed on the basis that it possesses only a little knowledge, which is seen as dangerous". Maserumule himself being the Editor of the Journal of Public Administration owned by the South African Association of Public Administration and Management wrote this important piece of argument as his first editorial message to assure the authors of the same journal that his ascension to editorial status could be an end of gate keeping in the said journal publication. Safe to say that his experience in the editorial chair of the same journal opposed his polemic editorial to justify that editorial "gatekeeping is the only solution to keep the integrity of scholarship of the Journal of Public Administration". While it can be argued that other functions exist in the peer review process of academic publishing and writing, it is important to acknowledge that no new or opposite system exists to replace the function of the peer review process in determining and ensuring high quality research in academia. Siler, Lee \& Bero (2014) also noted that "Peer Review is the only institution responsible for the evaluation and gestation of scientific research". Yi-Luen Do (n.d) argues that peer review "lies in the core of science and academic life" which implies that indeed no alternative mechanism exists to replace the peer review system to assess and control the quality of scholarly publication. There are, however, three common types of peer review in academic publications i.e. Single Blind Review, Double Blind Review and Open Peer Review.

\subsection{Single Blind Review}

In this typical peer review process one selected expert may be nominated by the Journal editor to review an article or a book for publication. The expert is an individual who is mostly trusted by the editor in objective evaluation of scientific material. Being an expert his opinion on the read material is final and cannot be questioned unless the Editor decides otherwise. His name is not revealed to the author or authors. In the modern publication environment this system can be used by established journals with high impact factors as their articles are read on the basis of established trust rather than of criticism. Emerging journals in developing countries may not be allowed to follow this model as they may be accused of not guarding against scientific quality control mechanisms.

\subsection{Double Blind Peer Review}

In this peer review process two experts are nominated by the journal editors to do a scientific evaluation of the manuscript. Like the Single blind Review model, the names of reviewers and authors are not revealed to each other. The approach adopted here is what is often called "Great Minds Think Alike". In a situation where the two reviewers agree on the quality of the assessed article the editor will decide to publish the article because great minds thought alike. In a situation where one Reviewer agrees to the quality of the assessed article and the other reviewer disagreed, the Editor chooses to accept or reject the article on his own or obtain a third opinion from another Reviewer other than the one who rejected it because Great Minds thought differently. Because of this dilemma of Great Minds failing to think alike sometimes, in reviewing many Journals of South Africa, ASAAF (Academy of Science of South Africa), recommended triple blind review for all South African journals in order to assess and improve quality of scientific publication in the country. Many South African journals and book publishers' use the double blind peer review process for article and book publication. 


\subsection{Open Peer Review}

In this peer review process two or three peer reviewers may be nominated by the journal editor to review a journal article or a book to be published. The difference between this peer review process and the other review process is that names of authors and reviewers are revealed to each other. This review process is mostly used by well-established book publishers and journals. Emerging journals in developing countries that try this model risk to be removed from the list of credible journal indexing institutions. The KamlaRaj publication in India uses the model in a risky way because they do not use a pool of their listed Reviewers but instead use the names of reviewers suggested by the authors themselves. The Open Peer Review Process can be abused if the publishers and editors of academic journals are negligent. Open Peer Review is not encouraged in many academic publishing as it is mainly vulnerable to abuse.

From these three models of a Peer Review Process it becomes clear that none of the process is mutually and exclusively favourably in ensuring quality and control of academic scholarship. The only and most important thing is that only Journals and publishing houses need to have a pool of experts' reviewers who should do justice to the text being evaluated for publication. The Single and Open Peer Review Process may not be a good model to follow today considering the commercial route academic publishing is taking today. One could argue that double or triple blind Review Process may help to assess and control quality of published material for scholarly consumption.

\section{THE EDITORS AND THEIR ROLE IN ACADEMIC PUBLICATIONS}

Lariviere, Haustein and Mongeon (2015) claim that the year 2015 marked the 350th of the creation of scientific journals in which he associated the origin to Journal des Scavans to France and Philosophical Transactions to the Royal Society of London. I cannot accept or reject that these are indeed the first journals created in 1665 to pursue scientific inquiry through a peer review process. The authors claim that those were the first created journals to advance scientific knowledge through avoidance of duplication of results. If that is indeed true that is where the role of the editor in scientific scholarship could have previously started.

An inspiration for one to be an editor should come from an individual's desire to promote scholarship in a subject area of expertise. It should indeed be about the love for disseminating knowledge and serving humanity and its science. Editors are responsible for ensuring that author feedback is compulsory and that it should be constructive (Scopus, n.d:2) rather than being destructive. Mainly because editorship is an academic community service with little or no remuneration from the Journal Editorial Boards many journal editors may take the editorial role to perform contradictory functions than those delegated to them. By virtue of their work Editors are custodians of a research record achieved for solving political, economic and social problems in the society. The inaccurate or accurate dissemination of information through their publication name does not safeguard them from the good or bad work produced by an author in their publication. Indeed journal editors are required to "adhere to universal standards and good practices" (Klenert \& Wager, 2010:1). To ensure the universal standards of ethics in published scholarly work, they themselves need to be ethically grounded in their editorial work. Thus far it's highly arguable to confirm the ethical principles by which journals editors conduct their editorial business. In generic terms there are basically four important roles of the Editor in Scientific publications: To promote the subject knowledge through proper publications of subject specific manuscript, to ensure ethical and Impartial review processes of manuscripts, Impartiality in accepting and Rejecting manuscripts, and Constructive and immediate feedback to authors.

\subsection{Promotion of knowledge through publications of subject specific manuscript}


Many journals today use a gatekeeping mechanism by which editors are the ones to firstly having to screen the article before it can go for peer review. Bowler (n.d:1) argues that journal articles are mostly rejected because they hardly fit the scope of the journal or are rather poorly written or have a poorly developed argument. Many journals indeed prefer this strategy; however, some journals claiming such a character publish in multi-disciplinary contexts. This they say is done to ensure that Reviewer's time is not wasted on a manuscript that does not fit the purpose of the journal (Editage Insight, 2013:2). Editors are indeed the most powerful mechanism of controlling knowledge dissemination through an academic journal. The editorial policy of many journals gives the editors an exclusive right to reject or to accept an article in spite of a positive or a negative report by independent reviewers. By and large, the reviewer's report does not determine the publishability of the article. Only the Editor uses the advice of the reviewer to take a decision about the suitability of a material to be prepared for publication. At the most a high number of reviewers rather recommend acceptance than rejection in publication (Editage Insights, 2013:2), therefore the role of the editor is significant in ensuring that the high level of acceptance is in the best interests of the journal's scope and mandate. Dow (n.d) opined that journal editors and referees assume a significant gatekeeper role within their disciplines and their academic professions.

\subsection{Ethical and Impartial review process of manuscript}

The ethical and impartial character of editors in publishing quality papers is highly contested in academic discourse. The original purpose of the academic journals which was mainly based on the professionalisation of the discipline and knowledge exchange among scholars is compromised (Weiner, 1998:1). Around the world today the primary purpose of a journal (Discipline and knowledge exchange) has become a secondary matter. Indeed many literature sources exist to attest that academic publishing today is used by the universities around the globe to compete on research volumes produced at university, to assist in distribution of research funds and to get better appointments at universities. Cherese, Oupa and Soul (2014) mentioned that the number of publications achieved by a university determines the ranking of a university in the scholarship acumen. The Universities around the globe have adopted the publish or perish approach in academia (Olukoju, 2002; Yi-Luen Do, n.d:2) making publication in scientific journals a prestige character of an academic. This according to Arnold (2009) has contributed to numerous cases of author misconduct and ethical embarrassment in scholarly publications. It's very difficult to determine the impartiality in the editors' selection of material for publication in the journal. Graf, Wager, Fiak, Scott-Lichter and Robinson (2007) posited that "Publishing occurs in an environment of powerful intellectual, financial and political interests that compete against each other", therefore making it difficult for editors impartiality and ethical principles to be maintained. As Weiner (n.d:4) argues the only "big "name in academia may influence both the editor and the reviewer to accept or decline a written article for publication. People's names in academia are normally better known than the merits of the manuscript submitted for publication. The same applies to those with lesser names in academia are likely to have their manuscripts rejected by editors at face value simply because their academic reputation in the academic circle is known to be of lesser value. Editors as human beings continue to attach better academic value to certain institutions and individuals of value. Such perceptions indeed undermine the primary purpose of scholarly writing. As I may argue from my own perspective of scholarly writing I can attest that no idea is not a good idea as long as the editor has a good sense of disseminating the authors' idea to the people. The editor has a moral responsibility to edit the idea to suit what the author wanted to convey to the scientific community.

\subsection{Impartiality in accepting and rejecting manuscripts}

It is known in the editorial environment that some journals do blind review and others do not do it at all (Armstrong, 1982). The painful ethical problem about this is that such acclaimed journals will claim that they conform to the double blind review process. In some journals as Arnold (2009) revealed of the 400 papers published by the journal El Naschie and indexed in Web of Science the Chief Editor wrote 60 of them which in all probability this self- 
publication by the author may reveal a shocking compromise of a peer review process by the Chief Editor himself. Roth (n.d) posits that while indeed publishing is important in academia we need to consider at least two important facts; firstly that writing is not every academic's forte or interest and that there is too much editorial abuse which is a double benefit for only reviewers and the editors themselves. This is possible mainly because when reviewers are given an opportunity to review others' manuscripts they might have an opportunity to write an argument better and submit it to the same journal for publication. Very few scholars may focus on this type of complaint and argument as it may be career limiting to them in academic publishing. Although the editors of journals today may hide behind the scope of the journals some mounting evidence suggests that personal differences in opinions between authors and editors have a direct bearing on the acceptability or unacceptability of the article in a publication controlled by specific editors in academic circles. Flood, Martin and Dreher (2013) opined that specific activism held by academics may compromise them as international journals may hold a specific philosophy opposed to activism scholarship. This inclination by scientific journals forces authors to write on issues they do not have interest on for purposes of fitting the publish or perish notion in academic institutions. It is indeed very clear that even if oversight institutions exists such as the Council of Science Editors and Editorial Committee, Editors' Forum in South Africa and others, very few authors may take their frustrations out on those institutions if feeling aggrieved by the unbecoming attitudes of editors of scientific journals on their alleged scientific work for fear of publication victimisation.

According to Scot-Lichter, Council of Science Editors and Editorial Policy Committee (2006:2) "the Editors of scientific journals have a responsibility to the public, the scientific community as a whole, the publishers of their journals, the authors who provide their content of the journals, the peer reviewers who comment on the suitability of the manuscript for publication and the journals readers". It is indeed very difficult for editors to go along the lines of prescription of regulatory bodies. Established and high impact factor journals today receive high volumes of submissions and therefore a short screening assists them to select and reject quickly articles that they do not wish to attend to (Editage Insights, 2013:2). Often it is not that such articles do not fit the purpose of the journal but in principle because they might not be coming from areas where the editor think creative and scientific contribution can come from. Most International journals are very discriminative in terms of scientific articles from developing countries because of clear focus on a specific geographical area. Relatively speaking there are academic journals in developing countries that publish scientific materials specific to their region. The Journal of Local Government Studies in the United Kingdom is very clear on its scope and focus that they only publish articles that address local government issues of their own country. Many journals especially those called international journals have specific geographical foci which discriminate against authors of specific geographical areas. Unfortunately, in their responses they may not tell their honest reasons of rejecting an article. Editors are not guided by impartiality of editorial ethics as their gate keeping character allows them "to control the quality of the journal by determining what ideas are let in and which ones are kept out" (Dow, 2000:147). Roth (2006) is of the opinion that often editors indiscriminately add up scores or recommendations of reviewers which compromises valid assessment of articles done by peer reviewers, hence invalidating the whole peer review process carried out by independent assessors of the manuscript.

\subsection{Constructive and immediate feedback to authors}

At the most modern journals gives a period of between 6 and 30 months to give a reviewer feedback (Bjork \& Solomon, n.d:2-3) which should also be constructive in character. In South Africa many scientific journals go for between 6 weeks and 6 months at the most. The problem, however, is that even though the feedback could be speedy, the publications can take more time. Depending on the publicity of journals and their open scope for disciplines the management of the high volume of articles received may not be on the same level with South African journals which at the most only publish South African materials. Although 
editors are expected to provide feedback some journals it took time until the author changes to submit the article somewhere else.

\section{THE STATUS OF RESEARCH AND PUBLICATION IN AFRICA}

Africa is underdeveloped and faces problems of chronically poor power relations, including insufficient knowledge generation capacity, low connectivity, poor reliability and high costs (Eberhard, 2015). Africa is indeed one of the disadvantaged continents on the globe in terms of knowledge generation and innovation. Tijssen (n.d:61) noted that "the publications of peer reviewed scholarly and technical journals are seen as the prime output of high quality scientific knowledge production". The research and publications of research done is a process by which progress of countries are measured across the globe. Many countries around the globe spend most of their budget on research so that innovations are made to solve their social, economic and political problems. South Africa is known to have contributed less than $0.1 \%$ in world inventions between the period 2000-2004 (MacGrecor, 2008:2). Progressive research and publication currently remain in the hands of few countries in the global environment. In the lead of research and publication is the United States of America, European Union, and with Asia (Lilies \& Curry, 2010:11-17) being represented by China and Japan. Africa is far behind the global race in research production.

It is just unfortunate that in Africa Universities which are expected to lead in research projects have been "weakened by the combination of poor political management, insufficient public investment and the haemorrhaging of talent to the developed nations" (Kotecha, Walwyn \& Pinto, 2011:5). Although it is argued that with the highest number of African universities currently having access to internet and the libraries, the research and publication were expected to increase usage in volumes. Political and economic crises often have an impact on academic publishing in Africa. As Olukochu (2002:3) noted the economic crisis in Nigeria had a serious impact on academic publishing as most of the countries progressive academics crossed the borders to search for good opportunities outside their own home country. This problem does not only concern Nigeria as most countries in Africa experience turmoil that makes academic brain drain the most appropriate choice.

MacGregor (2008) noted that African researchers produce $1.8 \%$ of the world's scholarly publications. Only South Africa and Egypt account for most publications in scholarly publications of the continent. South Africa is the only country in the continent that spends the highest budget in Research and Development (SAccess, 2013:17) in comparison to counterparts. In a study conducted by Ochola and Ochola (n.d:1-20) about the status of publications by academic Librarians in South from the year 2002-2011, it showed that South Africa remains on top with 159 publications which is $65 \%$ of the total output, followed by Botswana with 39 publications which constitute 13\% and Zimbabwe with 21 publications which constitute $9 \%$. South Africa's comparative advantages to others in Africa cannot be dissociated from its research incentive to researchers in various universities. It is noted that unlike other countries in the globe, South African universities are showered with research funds to the extent that other researchers hardly use such allocated funds. But with the good research incentives in numerous South African universities and the publish or perish models researchers found themselves in led to a dire need to be productive in research output. The financial incentive to researchers has indeed assisted in increasing research output in Universities (Woodiwiss, 2012). An important aspect to note, however, is that South Africa alone cannot pull the research publication of Africa to uplift the status required of Africa to contribute significantly to the global village. African countries need to learn to increase and invest more of their budget in research and publications so that they support researchers to contribute to the knowledge generation than mere consumption of available knowledge of western ideals. While it is notable that African countries need to learn from South Africa in terms of investing in research and publication, it should be noted that as Africans we 
contribute very minimal to the research publications and innovation in the globe. The question is: Is lack of financial support to researchers the only problem of why research and innovation is low in Africa? Are we sure that our situation is not because of the knowledge gatekeeping in which we need recognition through publication in international journals? Is our philosophy and our epistemology acceptable in the international publication houses? These question though raised in some academic discourses but are rarely being attended to for solution.

\section{EDITORS, PEER REVIEW GATE KEEPING AND CONTRIBUTION TO DEATH OF KNOWLEDGE}

From the onset it should be known that the goal of scientific knowledge is to increase knowledge and understanding of the world in which we live (Thornhill, 1991; Nkuna, 2012). The goal of science is grounded on its ability to bring about new knowledge to assist in social, political, economic and technological solution. The editors of scientific journals assisted by the peer review process owe it to the nation to ensure that knowledge generation by new and old scholars is given the opportunity to get a public attention as they are the only means by which knowledge can be disseminated to the people. Most academic writings also confirms that editors and their peer review process are indeed difficult to be trusted with the knowledge they are supposed to disseminate to the nation. While Gate keeping over dominate the editorial scope, unethical practices to disseminate information does not help in the dissemination of new information. Cawley (2011) argues that peer review is a failing system as it is failing to deal with ethical challenges since it gives the reviewers an opportunity to redraft their argument obtained from the reviewed papers and present it better after rejecting a submission. The peer review system may therefore empower the "experts" in identifying potential paradigm competitors through submitted materials for review and to know exactly who challenged their orthodox and such person may relatively not get easy access to publishing the material.

It is known in the Field of Public Administration that Thomas Woodrow Wilson is called the Father of Public Administration. His article "The Study of Administration "published in the Political Science quarterly journal in 1887 is a source of the origin of study of the discipline of Public Administration today. Thornhill (2006) claims that his article is the most referenced in many Public Administration dissertations written in the discipline. The article though it was relevant to the scope of Political Science Quarterly, but the article was poorly written and cannot be comparable to the Proverbs of Administration written by Herbert Simon and published in the Public Administration Review in 1946 in which challenged the application of the scientific management principles in public administration. The point I am trying to put is that it not the structure that can determine the publishability of the article but rather the contribution to knowledge the article content conveys to the community of scholars. It is known in the discipline of Public Administration and its practice that Woodrow Wilson's model of public administration proposed in the article enjoyed and is still enjoying legitimacy. The question is: If Wilson's article was to be submitted for publication today, would it get published? The answer is a simple no because it would have been compromised on basis of academic rigour, structure and logical flow of scientific argument and lack of scientific reference methods in the text. While Wilson is praised for public administration innovation worldwide, there is no mention of the wise editor who gave Wilson's opinion an everlasting scholarship audience even many years after his death and, in which today his model serve for public administration in the globe and dominate most Public Administration curriculums. The question is: If Wilson's article would not have been given the exposure by the Political Science Quarterly would the editor not have not compromised new knowledge? Indeed Wilson could have been lucky because many sources argue (Cawley, 2011) that peer review of articles in scientific journals only became universal in the 1960s. As such the acceptance of ones idea to be disseminated to the scientific community rested on editors alone than the peer review process. 
Journal editors in their gate keeping mode emphasised the significance of their journal on basis of an impact factor which today is abused to determine the integrity of scholarship publications in which the metrics used is based on global distribution of authorship. How the distribution of authors around the globe had to do with quality is also relative and questionable since journals indeed being scientific publications should have a motive of solving the countries broad problems. Colledge and James (2015:61) indicated that the initial purpose of "the impact factor was postulated in 1955 as a means to assist librarians in collection management". Impact factor does not mean to have any significant bearing on quality scholarship and academic citation. There are many practical cases of high citation index in low impact factor journals and extensively low citation rate in high impact factor journals. To cite a few examples, a staff member at the University of Limpopo applied for an NRF rating on basis of what he thought to have achieved in academia. The applicant had 201 citations at the time of application in 2016. A full Professor in the Department of Business Management at the University of Limpopo hoped for an NRF rating. His application was declined because his best cited article was published in the African Journal of Business Management, a journal that had lost its ISI and the South African Department of Higher Education Accreditation. The question is: Was the NRF disapproval of the rating for the applicant in the best interest of Science? Should knowledge be pushed only through high impact factor journals or any journal that conduct a blind peer review although not listed with the best journals in the market?

In recent years the terminology "predatory journals" became popular through a Librarian called Jim Beall. Many scientists around the world turned their back on so-called high impact factor journals to journals that promised them speedy publication rate within a month. Some of the journals were high flagged despite them being indexed by the ISI (Thomson Reuters) and IBSS (International Bibliography of Social Sciences). The journals are often accused of publishing controversial articles and marketing for submission of articles for publication (Tin, Ivana, Biljana, Ljubica, Dragan, and Dusan, 2014) through electronic mails not even given to them by the author. While one may not agree with manner of peer review process in the so called predatory journals, but are the scientific community not forced to do that by the knowledge gatekeepers hiding behind the impact factor? What is the importance of science? Does its importance lie in the name of a high impact factor journal or a journal that disseminated a peer reviewed knowledge?

The name "predator journal" is not different from the "pseudo-scientific journals" in the Medical fraternity in which the orthodox medical scientists who fought for retention of their ideals referred to any-counter publication of their ideals as "Pseudo-Science" (Sebola, 2014) and any publisher who published their ideals were referred as "Pseudo-scientific journals". Differing views in knowledge generation cannot always be compared with lower quality, especially considering the fact that new knowledge generators lack resources to stand against experienced orthodox paradigms protected through long time accumulated skills, expertise and resources to fight for the retention of the status quo. Both the predators and the pseudo-scientific journals are lashed on their financial weakness. They indeed charge between 100 and 300 US dollars, which in South African rands it could be between R1200 and R3100 per article published. The South African journals such as Administratio Publica, Journal of Public Administration, Journal of Trans-Disciplinarity Science charge between R5000 and R12000 per published article depending on the number of pages. Such are highly rated journals and their page fees cannot make them predatory because the publication of a journal in South Africa depends on whether it is university or self-funded. The University of South Africa through its publication directorate of UNISA Press runs numerous journals in which no page fees are paid, however, entrance into publishing in those journals is not easy as in journals that use page fees in South Africa. There is often in South Africa and beyond a relatively slight correlation between fair access to scientific publication and journals charging page fees as opposed to difficulty to access to journals that do not charge page fees. Except on opinions, there has not been any conclusive evidence to suggests that journals charging page fees produces poor scientific materials because in South Africa 
many journals that charges page fees are highly rated in scientific indexing such as ISI and IBSS. The argument posed in this paper still remain as to whether knowledge can only be pushed through high impact factor publication houses or any journal that practices blind peer review? But also very safe to conclude that gate keeping by editors of scientific journals hiding through integrity of high impact factor can only result in death of new knowledge generation.

\section{CONCLUSION}

This paper has argued that Editors and their peer review process are a reason for the death of new knowledge generation of scholarship. Literature reviewed in the paper indeed confirms that as much as peer review is important, the manner in which it is used to judge knowledge is fraught with ethical problems which makes it impossible to be trusted. There are numerous challenges relating to the peer review mechanism which discredit the whole process and its integrity. Of high important is how the editors have to depend on experts in the field and cannot confirm their objectivity in the assessments as it is based on trust. Mounting evidence indeed exists that in the peer review process the reviewers are able to identify the upcoming scholars who challenges their perspective and can therefore deal with such by ensuring that the work does not get published by proving the editor with deconstructive comments. In this case not only the editor filters knowledge to the scientific community but also the reviewers do the same. The keeping of knowledge in the hands of the few and fighting anyone with an alternative knowledge characterise the scientific publication in all journals of our time. As the scientific community we need to look as to what matters: Whether the generation of knowledge is effected and expanded through high impact factor journals or through any peer reviewed journal. 


\section{REFERENCE LIST}

Accord, S.K. \& Earl-Noul, S., Harley, D. 2010. Peer review in academic promotion \& publishing: its meaning, locus \& future. Centre for studies in higher education. Available at http://escholarship.org/ uc/item/1xv148c8\#

Acord, K.S. \& Harley, D. 2011. Peer Review in Academic Promotion and Publishing: Its Meaning, Locus, and Future. UC Berkeley: Center for Studies in Higher Education. Available at http://escholarship.org/ uc/item/1xv148c8

Ancker, J. \& McLellan, F. 2003. The Journal's role in scientific misconduct. A council of science editors retreat, 7-9 November 2003, Landsdowner Resort \& Conference Center, Virginia: 1-19

Armstrong, J.S. 1982. Research on scientific journals: implications for editors and authors. Journal of forecasting, 1 (1):83-104

Arnold, D.N. 2009. Integrity under attack: the state of the scholarly publishing. News journal of the society for industrial and applied mathematics, 42(10):1-3.

Barzilai-Nahon, K. 2009. Gatekeeping: A critical review. American society for information science and technology, 43(1):1-79.

Barzilai-Nahon, K. 2009. Gatekeeping: Acritical review. American society for information science and technology, 43(1):1-79.

Bijana, B., Dragon, M., Dusan, S., ljubica, B.L., Ivana, B., Tin, L. 2014. Predatory and fake scientific journals/publishers -a global outbreak with rising trend: a review. Geographic pannonica, 18 (3):6981. Doi: https://doi.org/10.5937/GeoPan14030691

Bjork, B-C \& Solomon, D. 2013.The publishing delay in scholarly peer-reviewed journals. Journal of informatics, 7(4):914-923. Doi: https://doi.org/10.1016/j.joi.2013.09.001

Bouhnik, D. \& Giat, Y. 2015. Information gatekeepers - Aren't we all? Informing Science: the International Journal of an Emerging Transdiscipline,18:127-144. Doi: https://doi.org/10.28945/2270

Bowler, S. 2008. Common reasons why academic papers are rejected by journal editors.https://www. deakin.edu.au/_data/assets/pdf_file/0010/704449/reasons_papers_rejected-24.08.pdf. Accessed 15 February 2017.

Bowman, A., Fiack, S., Graf, C., Robinson, A., Scott-Lichter, D., \& Wager, E. 2007. Best practice guideline on publication ethics: a publisher's perspective. International journal of clinical, (152):1-26. Doi: https://doi.org/10.1111/j.1742-1241.2006.01230.x

Cassidy, W.P. 2006. Gatekeeping similar for online, print journalists. Newspaper research journak $27(2)$ : 6-22. Doi: https://doi.org/10.1177/073953290602700201

Cawley, V. 2011. An analysis of the ethics of peer review and other traditional academic publishing practice. International journal of social science and humanity< 01 (03):205-213. Doi: https://doi. org/10.7763/ijssh.2011.v1.36

Chireshe, R., Oupa, L., Soul, S. 2014. Challenges in academic publishing: Editor's views. Journal of Communication, 5(2):95-100. Doi: https://doi.org/10.1080/0976691x.2014.11884829

Clayman, S.E \& Reisner, A. 1998. Gatekeeper in action: editorial conference and assessments of newsworthiness. American sociology review. 63 (2):178-199. Doi: https://doi.org/10.2307/2657322

Colledge, L. \& James C. 2015. A basket of metrics- the best support for understanding journal merit. European science editing, 41(3):61-65.

Dow, R.F. 2000. Editorial gatekeepers confronted by the electronic journal. College and Research Libraries, 61(2): 146-154 Doi: https://doi.org/10.5860/crl.61.2.146

Eberhard, A. 2015. Powering Africa: Facing the Financing and Reform Challenges. AFD Research Paper Series. 2016-21:1-14.

Editage Insights. $\mathbf{2 0 1 3}$. Peer review process and editorial decision making at journals. Available at http:// www.editage.com/insights/peer-review-and-editorial-decision-making-at-journals-0. Accessed 15 February 2017.

Eichholz, M., Eunyi, K., Shoemaker, P. \& Wrigley, B. 2001. Individual and routine forces in gatekeeping. Journalism \& Mass Communication Quarterly. 78 (2):233-246. Doi: https://doi. org/10.1177/107769900107800202 
Flood, M. G., Martin, B. \& Dreher, T. (2013). Combining academia and activism: common obstacles and useful tools. Australian Universities Review, 55 (1): 1-21.

Graf, C., Wager, E., bowman, A., Fiack, S., Scott-Lichter, D. \& Robinson, A.2007. Best practice guideline on publication ethics: a publisher's perspective. International Journal of Clinical Practice 61(152):1-26. Doi: https://doi.org/10.1111/j.1742-1241.2006.01230.x

Haustein, S., Lariviere, V. \& Mongeon, P. 2015. The Oligopoly of Academic Publishers in the Digital Era. PloS ONE. 10 (6):1-15. Doi: https://doi.org/10.1371/journal.pone.0127502

http://www.universityworldnews.com/article.php?story=20150226104329253.Accessed.15 February 2017.

Kars, Van Thiel, Van Der Graaf, Moors, De Graaf \& Van Delden, 2016. A systematic review of reasons for gatekeeping in palliative care research. Palliative Medicine. 30(6): 533 -548. Doi: https://doi. org/10.1177/0269216315616759

Kleinert, S. \& Wager, E. 2010. Responsible research publication: international standards for editors. A position statement developed at the $2^{\text {nd }}$ world conference on research integrity, Singapore, July 22-24, 2010, in Meyer, T. and Steneck, N (eds) Promoting research integrity in a global environment. Imperial College Press/world scientific publishing, Singapore: 3-28.

Kotecha, P., Pinto, C. \& Walwyn, D. 2010. Deepening research capacity and collaboration across universities in SADC: a Southern African universities regional. research and development fund, Southern African Regional Universities Association. Southern African Regional Universities Research and Development Fund, 3-28.

Lillis, T., \& Curry, M.J. 2010. Academic writing in a global context: The politics and practices of publishing in English. London: Routledge.

Lipworth, W. \& Kerridge, I. 2011. Shifting power relations and the ethics of journal peer review. Social epistemology, 25 (1), 97-121. Doi: https://doi.org/10.1080/02691728.2010.534567

MacGregor, K. 2008. Africa: researchers lag in science and technology. Available at http://www. universityworldnews.com/article.php?story=2008112015320645 accessed on 15 February 2017.

Olukoju, A. 2002. The crisis of research and academic publishing in Nigerian Universities: The twentieth century and beyond. Presented at the 28th Annual Spring Symposium: African Universities in the Twenty-First Century, University of Illinois/CODESRIA, Dakar, Senegal.

Rosengren, K.E.1997. Different sides of the same coin: Access and gatekeeping. This article was first presented as a personal festschrift for Denis McQuail, at the opening conference of the Amsterdam School of communication Research, 18-19 September: 3-12.

Roth, W.M. 2002. Editorial power/authorial suffering. Research in Science Education, 32(2): 215-240.

SAccess, 2013. Supporting the EU access to South Africa's research and innovation programmes. Report on South African research and information capacity. ACCESS4EU-South Africa, 243851:1-69.

Sato, I. 2012. Gatekeeper as a metaphor and concept. Hitotsubashi journal of commerce and management, $46(1): 41-50$.

Scopus. 2014. Frequently asked Questions (FAQs): The role of an editor. https://www.elsevier.com/data/ assets/SCFAQ-Role-of-an-Editor-22092014.pdf. Accessed 14 February 2016.

Scott-Litcher D, and the editorial policy committee, council of science editors, 2006. SCE's white paper on promoting integrity in scientific journal publications. Reston, Va: CSE.

Shoemaker, J.P. \& Vos, P 2009. Gatekeeping theory. London: Routledge.

Siler, K., Lee, K. \& Bero, L. 2015. Measuring the effectiveness of scientific gatekeeping. PNAS 112 (2): 360-365.

Tijssen, R. 2015.International cooperation-boosting African research. Available at www.chet.org.za/files/ resources/04\%20UWN_Special_Edn_4.4_Dakar2015.pdf

Weiner, G. 1998. Scholarship, disciplinary Hegemony and Power in Academic Publishing. Paper presented at the European conference for educational research, university of Ljubljana, Slovenia September $17^{\text {th }}$ to $20^{\text {th }} 1998$.

Woodiwiss, A.J. 2012. Publication subsidies: challenges and dilemmas facing South African researchers. Cardiovascular Journal of Africa, 23 (8): 421-427.

Yi-luen D. E. 2003. Afterword why peer review journals? International journal of architectural computing.1 (2): 253-265. Doi: https://doi.org/10.1260/147807703771799229 
Sebola, MP 2014. Research in South African Public Administration: The Paradox of Science, Politics and Economics of a Public Policy . Bangladesh e-Journal of Sociology, 11( 2):29-40.

Notes from reviewers

The article is a timeous one and addresses important issues. It does need to be very thoroughly language-edited (to be done by editorial board).

There are a few queries (marked in the manuscript) which should be attended to by the author.

The article can then be published. 